\title{
Effects of Lockdown across Nation
}

\author{
Amol Kawde \\ Medical Intern, Department of Community Medicine, Jawaharlal Nehru Medical College, Datta Meghe \\ Institute of Medical Sciences (DU), Sawangi (Meghe), Wardha, Maharashtra, Pincode-442001, India; \\ Email - kawdeamol1997@gmail.com \\ Review Article \\ Conflict of Interest: None
}

\begin{abstract}
:
COVID 19, is an infectious sickness, arisen toward the finish of last month of 2019, at Wuhan wet market, Hubei province PRC. This illness is spiralling out of control and quickly spreading around the world, overburdening the wellbeing framework with recently contaminated cases.

As of 7 January 2021 COVID, has infected over 87.4 million cases worldwide with 1.8 million deaths. In India COVID has infected over 10.4 million people with one lakh fifty thousand deaths.

The COVID-19 pandemic and the lockdown measures adopted to prevent the spread of the disease had a huge impact on a personal, social, and economic level for the world.

Numerous nations across the world are actualizing the confinement measures to check on the SARS-CoV-2 pandemic and to keep up the malady at reasonable levels. The current review reacts to these requests and endeavours to spread light on the effect of solitary. Our assumption from the review is the execution of solitary has compelled various sovereign state in smoothing the plague twist with fortifying the clinical administrations methodology and brush up the natural calibre.
\end{abstract}

Keywords - covid-19, illness , pandemic , lockdown .

\section{Background:}

An instance of obscure pneumonia in later months of 2019 was accounted for in Wuhan, PRC. The symptomatology of this illness was a lot of like pneumonia. Examination of manifestation tests by the Chinese Centre for Disease Control and Communication (CDC) authoritatively proclaimed that illnessis due to novel COVID-19 and named it as novel COVID19 pneumonia. Later on, January seven, 2020, the World Health Organization (WHO) formally stated it as COVID-19. Initially, instances of SARS-CoV-19 detailed that it could be not so much as serious as SARS and MERS, however later, the infection was hauling quickly between humans, hence the proof recommended that novel COVID-19 is more an irresistible sickness [1-3]

Coronavirus is a respiratory disease, which influences numerous individuals in an unexpected way, and contaminated individuals will get gentle to-direct side effects, generally seen following 2-14 days. Basic side effects incorporate pyrexia, cough, sniffling, rhinorrhoea, pharyngitis, and diarrhoea. The National Institutes of Health announced that small kids, individuals over 60 years or more seasoned, pregnant ladies, and individual's fundamental illness states have a towering danger of getting tainted with the infection and inclined to mortality. Ventilatory organ contaminations ordinarily send from individual to individual by beads fluctuating of various dimensions, when the breadth of bead size is greater than 5 micro meteris termed respiratory beads and less than five micrometres is termed bead nuclei. As stated by WHO, the unfurl of COVID-19 is fundamentally through ventilatory system beads and contiguity.[46]

\section{Safety lock - lockdown}

A rise convention forestalls the spread of disease between people from remaining in a given zone. The lockdown convention typically permits basic supplies, for example, drug stores, medical clinics, banks, and basic food item shops and shut 
down of all trivial exercises all through the period. Around the globe, the majority of the nations including land of liberty, Great Britain, Italia, PRC, republic of India and more are executing lockdown convention to control the spread of SARS-CoV-19. [7]

\section{Separating oneself:}

Separating oneself likewise called as bodily separating is a non-drug intercession or effort attempted to forestall the spread of infectious illnesses by diminishing the nearby association between the person. It normally includes evade of social occasion and keeping an actual separation from every other. This could be, a standout amongst other method of controlling the spread of sickness without accessible drug remedies. The purpose for the social removing is to diminish the flare-up of an irresistible infection. Disease transmission specialists evaluate the power of episode of COVID19 utilizing Ro number, not at all like severe acute respiratory syndromewidespread in year two thousand three, Haemagglutinin 1Neuroamidase $1 \mathrm{flu}$ during year two thousand nine, and Ebola during yeartwo thousand fourteen. Ro shows the propagation amount which portrays a normal figure of patients acquiring contamination during the irresistible period. Ro could be quantifiedwith the helpof accompanying recipe.

$R_{\mathrm{O}}=p \times$

c $\quad \times$

D

Where, $P=$ probability of transmission per exposure, $\mathrm{c}=$ number of contacts per unit time, and $\mathrm{D}=$ duration of infectiousness

As per the information on disease transmission experts, if $\mathrm{RO}$ is over one contamination will get pestilence, $\mathrm{RO}$ is equivalent to one disease will get endemic, and on the off chance that RO is less than one, at that point the contamination will vanish. A prior examination by Tim Churches investigated March three, two thousand twenty, that the regenerative amount of SARS-Cov-19 in the land of liberty goes from one point four to six point five on a normal of two point five, which demonstrates that contamination will get plague in the futureepoch. Analysts representing honourable Indian Council of Medical Research and Imperial College, London, recommended that the pandemic of SARS-CoVmanifestation can be diminished till $62 \%$ on condition that isolation and separating oneself are carefully obeyed. Correspondingly, numerous examinations had announced that the spread of SARS-CoV-19 can be constrained by keeping up physicalseparation. Thus, the principle point of social separating is to lessen the multiplication or R esteem under one. Like SARS-CoV, during the year nineteen fifty seven up till year nineteen fifty eight Influenza disease named as Asian flu contaminated half of the populace however on executing isolation, physical separation and regulation measures, this pandemic was diminished by over $90 \%$ was noticed.[8-10]

\section{Lockdown in India:}

Until now its first instance of SARS-CoV19 being accounted for on January thirty, republic of India had wrought quickly to proclaim one of the globe's biggest crosscountry lockdowns, affecting 130 crore people, which was adulated by the World Health Organization as being 'extreme and convenient'. Regardless of these appraises, in any case, it was accounted for that at a certain point, Republic of India was the third most contaminated nation overall. It merits interrogating, what components may have granted towards the disappointment of what at first resembled auspicious measures? [11-13]

In a nation accompanied by a lot between city movement, the closure of public vehicle constrained lakhs into improvised havens, prompting their depending on food freebees and the utilization of communal latrines bringing about social removing become hard to actualize. Moreover, it was noticed that lockdown measures brought 
about the most unfortunate and most minimized citizenry (who make up roughly 400 million casual specialists), who have the most un-financial ability to battle the pandemic without work and pay, prompting further destitution and starvation. Regardless of government vows to give edibles and basic stockpile to those in most need, these were regularly encouraged by casual stockpile ties that were handily disturbed during the isolate period. This would thus take steps to adversely affect constancy to social removing and lockdown sovereignty.[1416]

Furthermore, another danger toward the reaction to solitary possesses being the dissemination of deception among the social driveby frenzy, shame, and fault. Across the network degree, expanding degrees of savagery opposing medical care laborers as well as vilification of people associated or affirmed with approved COVID-19 be able to affect individuals from civic audience announcing indications and looking for help. Culturally, the widespreadturned out to be utilized to fuel hostile to Islamic conclusion, subsequent allegations of a social affair in the gathering Tablighi Jamaat look to be faulted for the shake out of numerous instances, repeatedly intensifying an atmosphere of vilification and viciousness in a nation where oppression strict the outnumbered has been on the ascent as of late. These mirror the centrality of ministerial, social, and monetary components as causations of the general accomplishment of solitary arrangements, which will be able todonate towards en routeto contamination. $[17,18]$

\section{Lockdown in UK:}

The UK government achieved lockdown plan on March twenty three, 2020, setting up limitations on community basedconnection, adapting functionalrequirements, with critical decrease to widespread administrations. These plans were viewed as effective in decreasing channelling of corona illness; the Scientific Advisory Group for Emergencies (SAGE) revealed that $\mathrm{R}$ toward the start of the widespread disease went from two point seven to three contingent upon the locale (for example usually three individuals are affected from one contagious person), during finish of July month $\mathrm{R}$ decreased to point five to point nine. [19]

Notwithstanding, regardless of this achievement in the decrease of channelling, lockdown plans are viewed as a method for fuelling wellbeing disparities. One of the eminent outcomes of lockdown gave on people in general is to their emotional wellness (mental health). It has been noticed that increased segment hazard context, for example, gender, lifetime,financial assets prior to the widespread stay significant causationin people emotional well-being along the widespread. Notwithstanding, mental health fluctuations along this time period has being considered as not equally circulated among the populace. Extra elements that have likewise affected weakness is intense monetary trouble (for example low pay, joblessness), family unit climate (homegrown maltreatment, living alone, or with small kids) and being a keyworker with openness to likely disease. Defensive variables have incorporated the individuals who stay with more significant stages of financial security; the decrease in driving, adjustments to training along with work exercises furthermore additional moments with loved ones might have diminished stress to a certain degreealong with indeed advanced highercognitive prosperity. This shows lockdown may have seen a possiblestepwhich could benefits those financially advantaged along with negative to those oppressed.[20,21] Likewise, the pandemic can be viewed as developing previous imbalances, uncovering weaknesses inside social, political and monetary frameworks, which therefore enhance the biomedical effect of the pandemic. While clinicians should zero in on moving toward singular patients in 
an all-encompassing biopsychosocial way, seeing that components, for example, sexual orientation long with breed expanded negative results in the great Britain (expanded paces of joblessness, mortality and breaking down emotional well-being) we ought to likewise endeavour to destroy structures inside the health authority of great Britain (NHS) and organizations whichfunctionon it incline along with disservice certain gatherings to these results.[22, 23]

\section{Lockdown in people's republic of china:}

As of January twenty two, the all-out number of affirmed cases had arrived at five hundred eighty one all around the world; there were five seventy one cases announced in PRC, three seventy fivesufferers were documented at Hubei region of PRC. After innumerable investigations in the nation detailed human-to-human transmission, along with quick dissemination of SARS-CoV inside 'Hubei' region, the Chinese professionalsincreased field of application of theirinterruptiveoperations along withimplementation of lockdown in Wuhan city and Hubei territory urban communities, on first month of 2020 bytwenty four date they implemented certain measures such as sealing off air terminals sealing off all open transportation (cars, public transport, roadways, railways etc ) it prevented people by entering or leaving the region. This action plan by the Chinese professionals was implemented one day prior to the spring festival in PRC resulted in reduction in transmission of sickness from one to. Furthermore, every store was sealed off except those supplying foodstuff, medical supplies and exceptionally social separation was followed along the region according to guidelines by PRC professionals. PRC public authorities cancelled all the practices which require social gathering with large groups and closed all the educational institutions. Adding to it, in workplaces educational institutions large cleaning efforts were carried out to outlook danger present due to virus in the place. $[24,25]$

This enormous scope isolated and collective separating that bolted numerous of persons and resulted in cost colossal personage and capital expenditure has never-ever beenexecuted to suchmagnitude, which eventually resulted in ailment transmission specialists wary of itshallfunction. Yuan intricately researched the impact of Wuhan's lockdown in the period COVID-19 pestilence and positively implicated that "urban areas lockdown merged with cross-country traffic limitations and Stay in Home Movement are on the wholesome wellbeing convergence that transitioned to quick increasing bend of priorly analysed disease manifestation and helped in bringing down plague." As for the explosion in the number of cases after the lockdown, Zhong et al. revealed strong connection within the five millions of pupils who migrated from Wuhan inside Hubei territory and various regions prior tofirst monthtwenty for, 2020, and the degree of enhancement of the flare-up of COVID-19 in PRC.[26, 27]

Another intervention taken is producing every day analysis for the recently suspected, analysed, and asymptomatic cases and passing. When a SARSCoVclinical case is analysed or doubted, the mindful specialist is needed to record the case via electronic means, where insights would be created for all-out amount in every region. The following reports are created through the China's Nationwide Infectious Disease Information System (IDIS) created in the year 2004 post the severe acute respiratory syndrome flare-up, and depend on the National Disease Reporting System (NDRS) in between the National and Provincial Health Commissions, which invariably the whole populace of PRC. Every area is needed to present its record of report consistently, where epidemiology related 
bends shall be produced for the entire nation and also for every region independently. These pestilence bends, notwithstanding the distributed writing and on location visits to the influenced regions, helped the disease transmission specialists in China to mention epidemiological objective facts about the illness' segment qualities, zoonotic inceptions, transmission elements, and movement. The nation likewise utilized this information to recognize and zero in on regions that have increased number of cases and require further interventions.[28]

Given the pattern of day-by-day increment in the quantity of revealed cases in PRC in January 2020, it was an obvious indicator for the public authority that sufferer would before long overpower the nation's clinics. Similarly, as seen in the Xiaotangshan Hospital that was worked in the time of the severe acute respiratory syndrome episode to alleviate the overemphasized clinical framework, PRC chose to duplicate the past experience and quickly began fabricating latest medical clinics in Wuhan and setting up the accessible ones to get SARS-CoV-19 patients. The choice was made in the month of January twenty four to assemble Huoshenshan Hospital in infectious city, a fresh out of the box new office that is completely prepared and has the ability to cater tothousandSARS-COV patients on the double. The structure of the 269,000-square-foot clinic was finished inside ten days and began getting patients on February third. At the sameduration, the Leishenshan Hospital related project with a fifteen hundred bed limit was declared and finished on February 5[29]

\section{Environmental changes due to lockdown:}

To decrease the spread of novel COVID19, the greater part of the nations across the globe embraced lockdown. This activity has put cars, prepares, planes, and major mechanical movement on hold. Because of this, unrivalled abatement in air contamination is being seen in the majority of the nations. During solitary, as per the authoritative pollution control body CPCB of republic of India, air grade list was enhanced up to $90 \%$ in significant urban communities of India including cities like Delhi, Mumbai, and Northern India's numerous modern regions. A new report detailed that PRC has discovered a major help in anthropogenic contamination emanation which brings about a twenty five percent decrease in carbon mission and a thirty percent decrease in nitrous oxide level during solitary. The world health organisation vigilantly reports that over ninety percent of the worldwide populace are stayingat the region where the nature of air is beneath the rule stage. A surrounding atmosphere contamination executes almost seven million individuals every year across the earth, and dominant part of the passing are in PRC and Indian subcontinent. An expansion in nitrous oxide has connected to different illnesses likelung ailments, cardiac conditions, diabetes, bronchial asthma and ongoing obstructive aspiratory sickness, and blood pressure related infections and expanded pace of hospital admissions. The casualty pace of SARS-CoV-19 is essentially higher with the sufferer who previously had prior medical issue, explicitly those suffering from cardiac sickness, diabetes, and lung related illness, and these infections are emphatically associated with the atmosphere contamination. Notwithstanding that, the nature of aqua has seen a huge development since authorization of the strict lockdown closes the unloading of modern waste. As indicated by $\mathrm{CPCB}$, out of thirty six water observing focuses, twenty seven had demonstrated betterment in the nature of aqua of stream of holy river. The accompanying boundary information were estimated to survey the nature of aqua of the stream: biochemical oxygen interest (<2 mg/l), broke up oxygen $(>6 \mathrm{mg} / \mathrm{l})$, e coli level (500/10 ml), and $\mathrm{pH}(6.5-8.5)$. Thus, the nature of air, aqua, and wellbeing records improved drastically 
after the total solitary, which straightforwardly assists with battling against the COVID-19.[30, 31]

\section{Psychological benefits of solitary:}

One of these elements is an arising feeling of split personality, and worry for other people, which emerges from a typical encounter of being in a fiasco. This inclination can be outfit by tending to people in general in aggregate terms and by asking "us "to represent the benefit of all and to help other people. At the point when discrete figures, they do as such in adjustment to standards. Their view of what others are doing or their opinion, others endorse or dislike, is from a characteristic craving to gain from them. During this solitary, since there is physical separation, individuals desire to acquire connection, despite the fact that the situation is unique.[32]

An investigation on various models of mass crisis conduct recommends a social mental reason for versatility. Standardizing approaches and alliance appear to be generally liked. They depend on the standards of self-order hypothesis, appreciating the mental idea of strength, and plausible conditions will enhance arranging of departure system, crisis administrations, and reasonable after-care methodology. It is fascinating to take note of that good and political direction were of less worry in examination with dread and tension side effect indicators on grumbling conduct. Dread and uneasiness indications drove people into consistence with vital general wellbeing practices, for example, individual cleanliness and physical distancing. Additionally, the recommended conduct change isn't recorded to have had any decrease in personal satisfaction. In certain cases, during the lockdown time frame, they function as normal and they coexist with family that cause them to feel greater instead of thinking about some other issues.[33, 34]

To master the expansion of infection, solitary is an exacting activity that must be trailed by all the residents who have a place with nation. Here, when individuals have confidence and faith in the public authority bodies and the specialists the manner in which the individual believes is totally unique contrasted with another situation [35, 36]. Members with higher faith in organizations displayed marginally less uneasiness about the COVID-19 pandemics. In any worldwide circumstance of life, dodging pressure isn't so natural. It isn't the sort of pressure or the measure of pressure that assumes a significant part in these sorts of circumstances. Or maybe, it is the outlook of the person which aids the individual or gathering of individuals to confront the circumstance powerfully and adjust the effect of circumstance[37-42]. Versatile outlooks about pressure could expand optimistic feeling and diminish negative wellbeing side effects. During this lockdown cycle, a few people as opposed to contemplating the pressure (infection) have embraced their way of life to the current circumstance. A sound attitude can completely transition the vision of a person [44-46].

\section{DISCUSSION:}

So, are the critics of lockdown wrong? If they argue that lockdown has failed to slow covid-19 in India, the, yes - but few people would make such a sweeping claim. Rather, the main criticism is that lockdown was a blunt instrument, poorly planned and cruelly implemented. This led to a lot of unnecessary misery which continues today. It also perhaps took attention away from other more sustainable strategies for disease control such as ramped up testing and tracing. Another valid criticism is that although lockdown has slowed disease, it has definitely not contained it.

\section{CONCLUSION:}

To control the spread of coronavirus outbreak in India. On $23^{\text {rd }}$ march 2020, the government of India under Prime Minister Narendra Modi ordered a nationwide 
lockdown for 21 days, limiting movement of the entire 1.3 billion population of India as a preventive measure against the covid19 pandemic in India and then the lockdown extension lead to many unwanted consequences that people had to face.

The most dramatic lockdown mistake was to bar migrant workers from returning home at a point when disease levels were low and any resulting spread could have been quite easily contained. The migrant crises teaches us first and foremost that both epidemiological and humanitarian consequences of any major move should always be considered carefully in advance. As restrictions are eased and more people travel home or return to work, robust mechanisms are needed to monitor and contain the new outbreaks which might follow. These mechanisms for disease surveillance must, of course, rely on transparency, communication and building trust.

CONFLICT OF INTEREST: none FUNDING: DMIMS

\section{REFERENCES:}

[1] Huang C, Wang Y, Li X, Ren L, Zhao $\mathrm{J}, \mathrm{Hu} \mathrm{Y}$, et al. Clinical features of patients infected with 2019 novel coronavirus in Wuhan, China. Lancet 2020;395:497-506.

[2] Eckerle I, Corman VM, Müller MA, Lenk M, Ulrich RG, Drosten C. Replicative capacity of MERS coronavirus in livestock cell lines. Emerg Infect Dis 2014;20:276-9.

[3] Shereen MA, Khan S, Kazmi A, Bashir N, Siddique R. COVID-19 infection: Origin, transmission, and characteristics of human coronaviruses. J Adv Res 2020;24:91-8.

[4] Esper F, Weibel C, Ferguson D, Landry ML, Kahn JS. Evidence of a novel human coronavirus that is associated with respiratory tract disease in infants and young children J Infect Dis 2005;191:492-8.

[5] Surveillances V. The epidemiological characteristics of an outbreak of 2019 novel coronavirus diseases (COVID-19)-China, 2020. China CDC Weekly 2020;2:113-22.

[6] Leung NH, Chu DK, Shiu EY, Chan $\mathrm{KH}$, McDevitt JJ, Hau BJ, et al. Respiratory virus shedding in exhaled breath and efficacy of face masks. Nature Medicine, 2020;1-5.

[7] Alvarez FE, Argente D, Lippi F. A simple planning problem for covid19 lockdown (No. w26981). National Bureau of Economic Research 2020;34.

[8] Hensley L. Social Distancing is out, Physical Distancing is in-Here's How to do it. Global News Canada; 2020.

[9] Koenig KL, Schultz CH. The 2014 Ebola Virus Outbreak and Other Emerging Infectious Diseases; 2014.

[10] Dietz K. The estimation of the basic reproduction number for infectious diseases. Stat Methods Med Res 1993;2:23-41.

[11] Malta M., Rimoin A.W., Hoff N.A., Strathdee S.A. The 2019-nCoV pandemic in the global south: a Tsunami ahead. EClinicalMedicine. 2020 May 19;23:100384. JUNE 01, 2020.

[12] Lancet $\mathrm{T}$. India under COVID-19 lockdown. Lancet (London, England) 2020 Apr 25;395(10233):1315.

[13] Ghosh A., Nundy S., Mallick T.K. How India is dealing with COVID19 pandemic. Sensors International. 2020 Jul 23;1 100021.

[14] Monitor I.L.O. 2020. COVID-19 and the World of Work.

[15] Kelley M., Ferrand R.A., Muraya K., Chigudu S., Molyneux S., Pai M., Barasa E. An appeal for practical social justice in the COVID-19 global response in low-income and middle-income countries. The Lancet Global Health. 2020 May 14;8(7) 
[16] Poddar M. The Citizenship (Amendment) Bill, 2016: international law on religion-based discrimination and naturalisation law. Indiana Law Rev. 2018 Jan 2;2(1):108-118.

[17] Scientific Advisory Group for Emergencies . The R Number in the UK. 2020. The R number in the UK.

[18] Pierce M., Hope H., Ford T., Hatch S., Hotopf M., John A., Kontopantelis E., Webb R., Wessely S., McManus S., Abel K.M. Mental health before and during the COVID19 pandemic: a longitudinal probability sample survey of the UK population. The Lancet Psychiatry. 2020 October;7(10):883-892.

[19] McManus S., Bebbington P.E., Jenkins R., Morgan Z., Brown L., Collinson D., Brugha T. Data resource profile: adult psychiatric morbidity survey (APMS) Int. J. Epidemiol. 2020 Apr 1;49(2) 361-2e.

[20] Andrew A., Cattan S., Dias M.C., Farquharson C., Kraftman L., Krutikova S., Phimister A., Sevilla A. Institute for Fiscal Studies; 2020. How Are Mothers and Fathers Balancing Work and Family under Lockdown?"

[21] Burki T. The indirect impact of COVID-19 on women. Lancet Infect. Dis. 2020 Aug 1;20(8):904-905.

[22] Siddique H. The Guardian; 2020. UK Government Urged to Investigate Coronavirus Deaths of BAME Doctors.

[23] Report of the WHO-China Joint Mission on Coronavirus Disease 2019 (COVID-19). 2020. Available from:

https://www.who.int/docs/defaultsource/coronaviruse/who-china-jointmission-on-covid-19-final-report.pdf.

[24] She J, Jiang J, Ye L, Hu L, Bai C, Song Y. 2019 novel coronavirus of pneumonia in Wuhan, China: emerging attack and management strategies. ClinTransl Med. 2020 Feb;9(1):19.

[25] Carlos WG, Dela Cruz CS, Cao B, Pasnick S, Jamil S. Novel Wuhan (2019-nCoV) Coronavirus. Am J Respir Crit Care Med. 2020 Feb;201(4):7-P8.

[26] Yuan, C. A simple model to assess Wuhan lock-down effect and region efforts during COVID-19 epidemic in China Mainland. medRxiv. Available from: https://www.medrxiv.org/content/10. 1101/2020.02.29.20029561v1.

[27] Zhu N, Zhang D, Wang W, Li X, Yang B, Song J, et al. A novel coronavirus from patients with pneumonia in China, 2019. N Engl J Med. 2020 Feb 20;382(8):727-33.

[28] Lihua Z, Kun L, Yining P, Yimeng $Z$. Workers race against time to build 'high-speed' hospitals. China Daily. 2020.

[29] Shrestha, Asheshwor M, et al. Lockdown Caused by COVID-19 Pandemic Reduces Air Pollution in Cities Worldwide. EarthArXiv 2020;3:1-27

[30] Han Y, Lam JC, Li VO, Guo P, Zhang Q, Wang A, et al. The Effects of Outdoor air Pollution Concentrations and Lockdowns on Covid-19 Infections in Wuhan and other Provincial Capitals in China; 2020.

[31] Lambert KA, Bowatte G, Tham R, Lodge C, Prendergast L, Heinrich J, et al. Residential greenness and allergic respiratory diseases in children and adolescents - A systematic review and meta-analysis. Environ Res 2017;159, 212-21.

[32] Van Bavel JJ, Baicker K, Boggio PS, Capraro V, Cichocka A, Cikara M, et al. Using social and behavioural science to support COVID-19 pandemic response. Nature Human Behaviour 2020;1-12.

[33] Drury J, Cocking C, Reicher S. The nature of collective resilience: 
Survivor reactions to the 2005 London bombings. Int J Mass Emerg Dis 2009;27:66-95.

[34] Harper CA, Satchell LP, Fido D, Latzman RD. Functional fear predicts public health compliance in the COVID-19 pandemic. International journal of mental health and addiction 2020;2:1-14.

[35] Šrol J, Mikušková EB, Cavojova V. When we are worried, what are we thinking? Anxiety, lack of control, and conspiracy beliefs amidst the COVID-19 pandemic. PsyArXiv 2020;2:1-19.

[36] Crum AJ, Jamieson JP, Akinola M. Optimizing stress: An integrated intervention for regulating stress responses. Emotion 2020;20:120.

[37] Nisargandha, M.A., and S. Dadaraoparwe. "Spread of Coronavirus Disease 2019 (COVID19) during the Lockdown in the Indian Population and Preventive Measures." International Journal of Research in Pharmaceutical Sciences 11, no. Special Issue 1 (2020): 32832.

https://doi.org/10.26452/ijrps.v11iSP L1.2721.

[38] Phansopkar, P., W.M. Naqvi, and K. Kumar. "Musculoskeletal Check in Smartphone Overuse in Covid 19 Lockdown Phase." International Journal of Research in Pharmaceutical Sciences 11, no. Special Issue 1 (2020): 438-41. https://doi.org/10.26452/ijrps.v11iSP L1.2807.

[39] Waghmare, A., S. Shrivastava, and S. Date. "Effect of Covid-19 Lockdown in Trauma Cases of Rural India." International Journal of Research in Pharmaceutical Sciences 11, no. Special Issue 1 (2020): 36568.

https://doi.org/10.26452/ijrps.v11iSP L1.2727.

[40] Wanjari, T.N., and G. Sawarkar. "Lockdown Lifestyle: Engaging the
Invisible Enemy." International Journal of Research in Pharmaceutical Sciences 11, no. Special Issue 1 (2020): 491-95. https://doi.org/10.26452/ijrps.v11iSP L1.2836.

[41] Behere, P.B., A.P. Behere, and D. Chowdhury. "Rise in Cases of Alcohol Withdrawal Following Lockdown in Dry District of Wardha." Journal of Neurosciences in Rural Practice 11, no. 3 (2020): 478-80. https://doi.org/10.1055/s0040-1712554.

[42] Gaidhane, S., N. Khatib, Q.S. Zahiruddin, A. Gaidhane, S. Telrandhe, and P. Godhiwal. "Depression, Anxiety and Stress among the General Population in the Time of COVID-19 Lockdown: A Cross-Sectional Study Protocol." International Journal of Research in Pharmaceutical Sciences 11, no. Special Issue 1 (2020): 360-64. https://doi.org/10.26452/ijrps.v11iSP L1.2726.

[43] Parwe, S.D., A.S. Ingle, M.A. Nisargandha, and B. Rathi. "Healthcare Workers Novel Coronavirus (NCOVID 19) LifeThreatening Situation during the Pandemic." International Journal of Research in Pharmaceutical Sciences 11, no. Special Issue 1 (2020): 122225 .

https://doi.org/10.26452/ijrps.v11iSP L1.3600.

[44] Rathi Saurabh, D., P. Nikhade, N. Motwani, S. Baror, and A. Jaiswal. "Coronavirus Pandemic-the Real Lessons Are Learnt in the Time of Crises." International Journal of Research in Pharmaceutical Sciences 11, no. Special Issue 1 (2020): 101114.

https://doi.org/10.26452/ijrps.v11iSP L1.3426.

[45] Sahu, A., and W.M. Naqvi. "Floating Countries and Corona Pandemic: Impact of Covid-19 on Stranded 
Cruise Ships." International Journal of Research in Pharmaceutical Sciences 11, no. Special Issue 1 (2020): 219-23. https://doi.org/10.26452/ijrps.v11iSP L1.2702.

[46] Bhombe, K., V. Baliga, P.V. Dhadse, and C. Subhadarsanee. "Coronaviruses Outbreaks - Then to Now." International Journal of Research in Pharmaceutical Sciences 11, no. Special Issue 1 (2020): 115155. https://doi.org/10.26452/ijrps.v11iSP L1.3571. 